violence in acute psychiatric wards locally by combining Jarman scores and data from annually published figures in the Criminal Statistics of England and Wales. Annual average per cent bed occupancy and nursing staff levels might also have predictive value and an index of these four factors might inform the local need for provision of intensive care or high dependency psychiatric units.

WALKER, W. D. \& CAPLAN, R. P. (1993) Assaultative behaviour in acute psychiatric wards and its relationship to violence in the community: a comparison of two health districts. Medicine, Science and the Law, 33, 300-304.

Richard CapLaN

Southern General Hospital, Glasgow G514TF

WILL WALKER,

HM Prison Manchester, M60 9AH

\section{Home versus out-patient psychiatric assessment}

Sir: In South Manchester 50\% of all newly referred patients to the Department of Psychiatry fail to keep their out-patient appointments. This is wasteful of medical time, permits mental illness to go untreated, and deprives medical students of valuable experience.

In the second and fourth quarters of 1992 new patients were therefore seen in their homes. In the first and third quarters of 1992 they were assessed in the out-patient clinic. Three new patients were appointed per clinic. In home-based assessments, the consultant took the medical student to the patient's home and introduced the student to the patient. The consultant then went to see another patient and returned an hour later.

Forty-six out of $59(78 \%)$ appointments at patients' homes and 30 out of 55 (55\%) appointments at psychiatric out-patient clinics were kept, a significant difference $\left(\chi^{2}=6.01, P=0.014\right)$. Home visiting often revealed diverse life circumstances and enabled a friend or relative to act as an additional informant. This aided the assessment of premorbid personality and functioning as well as their social, family and supportive relationships which has special relevance with respect to the care programme approach.

Over 12 months, 14 medical students participated in home-based, and 13 in hospital-based psychiatric assessments. Home visiting did require the use of the consultant's car and driving between six and eight miles an afternoon, which incurred on average an additional $\mathbf{3 0}$ minutes per clinic.

In an urban area, therefore, home visiting can lead to more new patients being assessed, and greater efficiency. The rate of availability for assessment was not as high as that found by some community based mental health teams (Burns et al, 1993; Jackson et al, 1993). However, most patients preferred their initial assessment to be at home and medical students found such assessments more interesting. It is possible to teach medical students psychological medicine in domestic settings as well as exposing them to the concept of caring for people in the community.

Burns, T., Beadsmoore, A., Bhat, A. V., et al (1993) A controlled trial of home-based acute psychlatric services: I. Clinical and social outcome. British Journal of Psychiatry, 163, 49-54.

JACKSON, G., GATER, R., GoLDBERG, D., et al (1993) A new community mental health team based in primary care. A description of the service and its effect on service use in the first year. British Journal of Psychiatry. 162, 375384.

CHRISTOPHER S. THOMAS

University Hospital of South Manchester. Manchester M20 8LR

\section{How caring is community care}

Sir: With the current ethos of 'community care', more of our patients are being seen outside of the hospital and out-patient clinic. In old age psychiatry this can give a deeper understanding of the interaction between a patient with dementia and their environment. It allows us to assess the safety and cleanliness of the home, as well as the patient's orientation and function within it. It also fits the 'politically correct drive' that sometimes occurs with community care.

In Swindon we are fortunate to have a compact catchment area, most of our caseload are within 15 minutes drive from the base hospital. As a consequence $80 \%$ of my patients (new cases and follow-up) are seen in their residence.

However, in the last month, three families, on asking have stated their preference for hospital consultations. In two cases it was a break from the daily routine, and in the other the carer felt it would ensure the patient got out of bed early.

I sometimes wonder if our drive for community orientated care runs contrary to the patient's desire. Hence to use the jargon. I have developed a more 'service-user led model of care delivery'.

\section{S. MANCHIP}

Department of Old-Age Psychiatry, Victoria Hospital, Okus Road. Swindon SN1 4JU

\section{Mad poets?}

Sir: I feel moved to comment on Hugh Freeman's review of Alex Mezey's book Muse in Torment (Psychiatric Bulletin, September 1995, 18, 588589). In particular, the concluding comment on 